\title{
Clinical presentation, diagnosis, pathogenesis and treatment options for lymphocytic colitis (Review)
}

\author{
MAGDY EL-SALHY $^{1,3}$, DORIS GUNDERSEN ${ }^{2}$, JAN GUNNAR HATLEBAKK $^{3}$ and TRYGVE HAUSKEN ${ }^{3}$ \\ ${ }^{1}$ Section for Gastroenterology, Department of Medicine, Stord Helse-Fonna Hospital, Stord; \\ ${ }^{2}$ Department of Research, Helse-Fonna, Haugesund; ${ }^{3}$ Section for Gastroenterology, \\ Institute of Medicine, University of Bergen, Bergen, Norway
}

Received February 24, 2013; Accepted April 29, 2013

DOI: $10.3892 / \mathrm{ijmm} .2013 .1385$

\begin{abstract}
Lymphocytic colitis (LC) is characterized by chronic or relapsing non-bloody watery diarrhea and a macroscopically normal colon. However, histopathological examination of colonic biopsy samples reveals an increased intraepithelial infiltration of lymphocytes ( $\geq 20 / 100$ enterocytes), and increased inflammatory cells within the lamina propria, but with a normal mucosal architecture. The reported prevalence of LC varies from 14.2 to 45 per 100,000 individuals, while its reported incidence is between 0.6 and 16 per 100,000 individuals. LC has a high rate of spontaneous symptomatic remission and is not associated with an increased risk of colon cancer or inflammatory bowel disease. The diagnosis is based on the histopathological findings. The density of colonic chromogranin A-positive cells provides an effective diagnostic tool with high sensitivity and specificity in both the right and left colon. Gastrointestinal infections, drugs, and/or autoimmunity may trigger chronic colonic low-grade inflammation. Colonic nitric oxide, serotonin and peptide YY (PYY) cell densities are markedly increased in patients with LC. It has been hypothesized that the low-grade inflammation in LC through the endocrine-immune axis causes this increase. It has been postulated further that these abnormalities in the neuroendocrine system of the colon are responsible for the diarrhea observed in patients with LC. The benign course and rate of spontaneous remission of LC denotes that drugs with severe side-effects should be avoided if possible. The drug cost and drug coverage may also be limiting factors for some patients. These aspects should be taken into account when making decisions regarding treatment options.
\end{abstract}

Correspondence to: Professor Magdy El-Salhy, Section for Gastroenterology, Department of Medicine, Stord Helse-Fonna Hospital, Box 4000, 5409 Stord, Norway

E-mail: magdy.el-salhy@helse-fonna.no

Key words: diagnosis, pathogenesis, chromogranin A, lymphocytic colitis, nitric oxide, serotonin

\section{Contents}

1. Introduction

2. Clinical presentation and course

3. Diagnosis

4. Pathogenesis

5. Treatment

6. Conclusion

\section{Introduction}

Read et al (1) introduced the term lymphocytic colitis (LC) in 1980 to describe patients with chronic or relapsing non-bloody watery diarrhea and an endoscopically and/or radiologically normal colon. However, a histopathological examination of colonic biopsy samples from these patients shows increased intraepithelial infiltration of lymphocytes and increased inflammatory cells within the lamina propria (1). The reported prevalence of LC in population-based investigations has varied from 14.2 to 45 per 100,000 individuals (2-8), while its incidence has been reported to be between 0.6 and 16 per 100,000 individuals (7-13). Although LC can occur at all ages, its incidence peak occurs at approximately 60 years of age, and females constitute $68 \%$ of patients with LC (14). Analysis of the prevalence and incidence of LC in different populations should, therefore, consider the age structure of these population pyramids (15).

Long-term epidemiological studies have found that the incidence of LC is increasing $(14,16)$; this could be a real increase or the result of an increased awareness of the necessity of examining colonic biopsy samples in patients with diarrhea without obvious etiology (14). In Örebro county (Sweden) and Olmsted county (MN, USA) where these studies were conducted, the awareness of LC has been high and constant during all of the investigation period, making it unlikely that this factor played a role in the observed increase in LC incidence. However, change in the age distribution during the long observation periods ( $>15$ years) may have an effect on this increase, since official Swedish statistics indicate a considerable increase in the proportion of individuals $>60$ years of age in Örebro county.

There have been several recent comprehensive reviews on LC (5,14,17-21). The present review takes a different approach 
from the others by aiming not merely to present an updated account of LC, but also to highlight the debated issues of clinical presentation, diagnosis, pathogenesis and treatment options.

\section{Clinical presentation and course}

The cardinal symptom for LC is chronic or recurrent nonbloody diarrhea $(22,23)$. The diarrhea is chronic in $33 \%$ and intermittent in $67 \%$ of patients with LC $(22,23)$. Patients with LC have 4.9 bowel movements per day on average; however, $22 \%$ of patients have up to 10 bowel movements daily $(5,14,21,23)$. Other symptoms occurring in patients with LC include abdominal pain and weight loss (24-27) (Table I). However, in some patients, constipation is the main symptom of LC (24-27). It is noteworthy that in clinical practice, colonic biopsies are routinely taken during colonoscopy of patients with diarrhea and a macroscopically normal colon, but not in those with constipation. It is therefore, not clear whether LC is exclusively a diarrheal disease.

The reported rate of spontaneous symptomatic remission in LC in follow-up studies has varied between 59 and 93\% (23,27). Histopathological normalization reportedly occurs in $82 \%$ of patients with LC after approximately 38 months of follow-up (23). A follow-up study over a 6.4-year period also found a high rate of symptomatic remission in patients with LC (28). Moreover, the risk of colon cancer or inflammatory bowel disease is not increased in patients with LC (29).

\section{Diagnosis}

The results of a physical examination, laboratory tests, small and large bowel radiology and colonoscopy are normal in LC, with the diagnosis instead being based on histological changes in colonic biopsy samples. The typical histological changes include an increase in intraepithelial lymphocytes ( $\geq 20 / 100$ enterocytes) and infiltration of inflammatory cells (mainly lymphocytes and plasma cells) in the lamina propria $(21,30)$. Although surface epithelial damage can be observed, the architecture of the mucosa is normal (Fig. 1) $(21,30)$. In clinical practice, the increase in intraepithelial lymphocytes is usually clearly evident with manual counting only required in cases with a borderline number of lymphocytes (21). The surface mucosa overlying lymphoid aggregates always contains higher numbers of intraepithelial lymphocytes; thus, these areas should be avoided when an LC diagnosis is being made (21).

While the histopathological diagnosis of LC is straightforward, it is unclear whether the histopathological changes observed in LC are diffusely distributed throughout the colon or limited to a certain segment(s). Certain studies have found the histopathological changes to be more prominent and easier to detect in the right colon (cecum and the ascending and right transverse colon) $(11,31,32)$, while other authors have maintained that biopsies obtained from the left colon (sigmoid and descending colon) are reliable for the diagnosis of LC $(10,33,34)$. These controversial results question whether colonoscopy with a segmental biopsy is required for the diagnosis of LC, or whether sigmoidoscopy is sufficient. Solving this issue is important for clinical practice, since the risk of complications, the clinicians labor and the economic burden
Table I. Clinical presentation of lymphocytic colitis.

\begin{tabular}{lrc}
\hline Symptom & Occurrence $(\%)$ & Refs. \\
\hline Diarrhea & $88-100$ & $10,22-26$ \\
Constipation & $2-43$ & 22,23 \\
Abdominal pain & $21-94$ & $21-23$ \\
Weight loss & $33-73$ & $22-26$ \\
Fecal urgency & $33-92$ & $10,22,23$ \\
Gas/bloating & $14-69$ & $10,22,25,27,28$ \\
Nocturnal stool & $25-59$ & $10,21-23,25,26$ \\
Fecal incontinence & $9-64$ & $10,21-23,25,26$ \\
Nausea & $16-19$ & 22,25 \\
\hline
\end{tabular}

are higher for colonoscopy than for sigmoidoscopy. Since this matter has not yet been resolved, several gastroenterologists perform colonoscopy with a segmental colonic biopsy to ensure an accurate diagnosis.

Chromogranin A is a 68 -kDa protein comprising 439 amino acid residues, which was isolated from secretory granules of the adrenal medulla (35). Chromogranin A is co-stored and co-released with monoamines and peptide hormones present in the adrenal medulla, pituitary gland, parathyroid, thyroid C-cells, pancreatic islets, endocrine cells of the gastrointestinal tract and sympathetic nerves (35-37). Chromogranin A is therefore considered to be a general marker for all endocrine cells. Some of the patients in a cohort of irritable bowel syndrome (IBS), showed an extremely high density of colonic chromogranin A-positive cells (Fig. 2), and were subsequently identified as having LC (38). This unexpected observation was confirmed in a larger cohort of patients with LC, and led to the colonic chromogranin A-positive cell density being proposed as a diagnostic marker for LC (Figs. 3 and 4) (39). The use of the chromogranin A-positive cell density as a marker for the diagnosis of LC has a high sensitivity (97 and 100\%, in the right and left colon, respectively) and specificity (98 and 94\%, in the right and left colon, respectively) (39). The time and cost associated with the use of this marker are the same as those for the detection of lymphocytes. Using the chromogranin A-positive cell density as a marker has several advantages: i) it has a high sensitivity and specificity in the left colon, thus sigmoidoscopy with biopsy can be used in the diagnosis; ii) it is not affected by the artifact caused by lymphoid aggregates and is thus useful in borderline cases where lymphocyte infiltration does not completely fulfill the definition of LC; and iii) it can be used to differentiate patients with LC from those with IBS, refractory celiac disease, lymphocytic enterocolitis, autoimmune enteropathy and lymphoma.

LC and IBS have similar symptoms and normal radiological and endoscopic appearances of the colon (40), which means that patients with LC are at risk of being misdiagnosed as IBS $(24,40-43)$. The task of differentiating between LC and IBS is made even more difficult by the fact that some patients with IBS exhibit an increase in the number of intraepithelial lymphocytes $(40,44)$. The use of colonic chromogranin A-positive cell density as a marker for LC may prove to be beneficial in such cases, since the density of this marker in the colon is low in patients with IBS (45). 


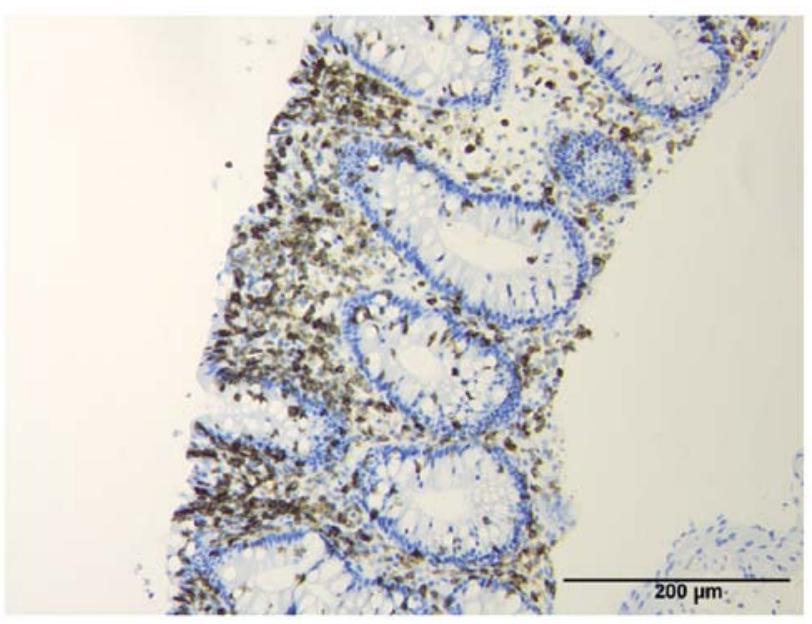

Figure 1. Photomicrograph of the colon of a patient with lymphocytic colitis showing immunostaining with antibodies against CD57, which is a marker for subsets of natural killer cells and $\mathrm{CD} 8^{+}$lymphocytes, and a small percentage of $\mathrm{CD} 4^{+} / \mathrm{CD} 45 \mathrm{R} 0^{+} \mathrm{T}$ lymphocytes.

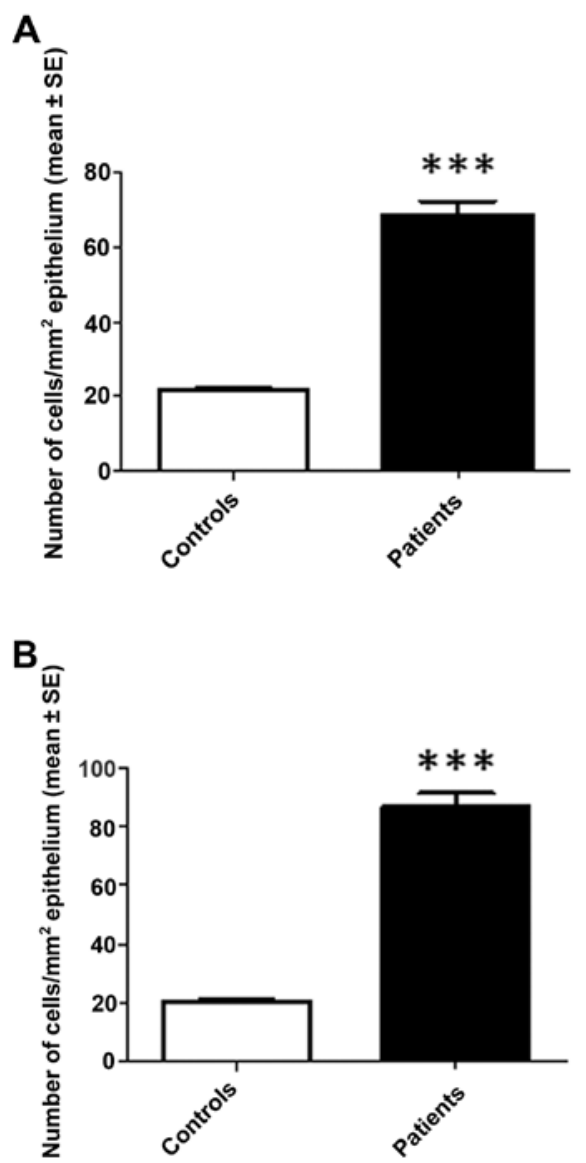

Figure 2. Chromogranin A-positive cell density in (A) the right and (B) the left colon of patients with lymphocytic colitis and healthy controls. ${ }^{* * *} \mathrm{P}>0.001$.

Celiac disease has been reported to be associated with LC; between 4.3 and $31 \%$ of patients with celiac disease exhibit histopathological changes typical of LC (46-48). Approximately $7 \%$ of patients with LC have celiac disease $(6,10,23,25,49-51)$. It has been speculated that colonic lymphocyte infiltration observed in the colon of patients with celiac disease is part
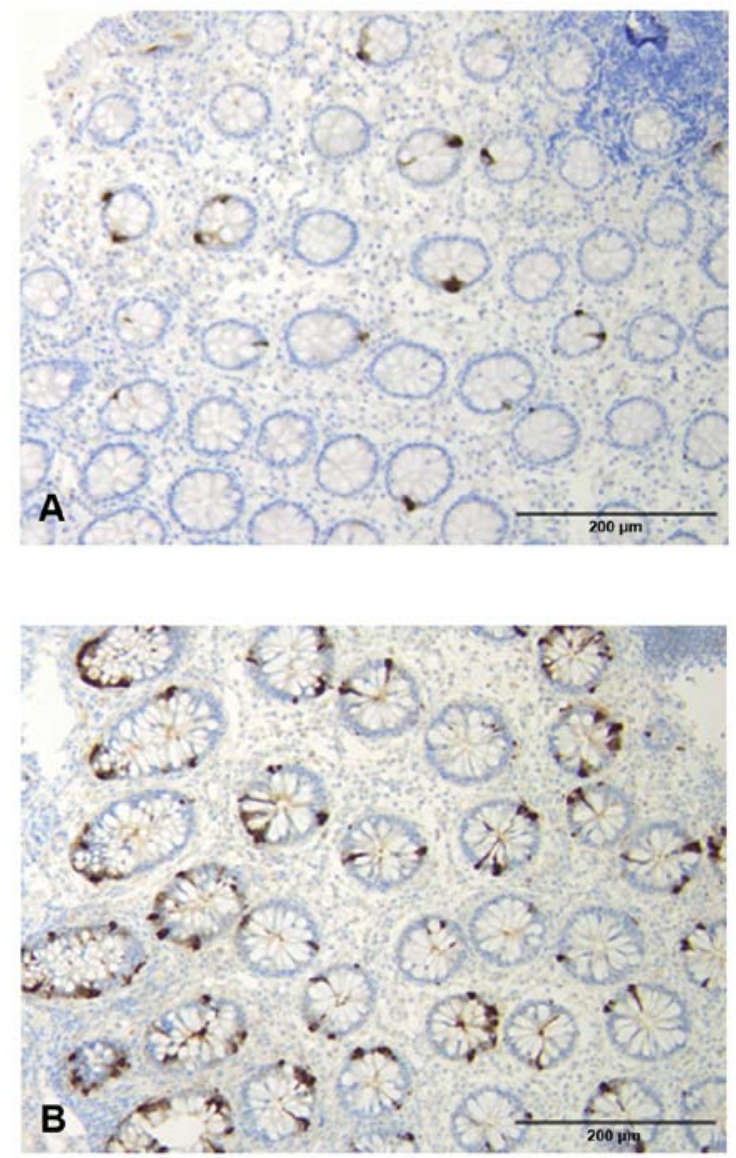

Figure 3. Chromogranin A-immunoreactive cells in the colon of (A) a control subject and (B) a patient with lymphocytic colitis.

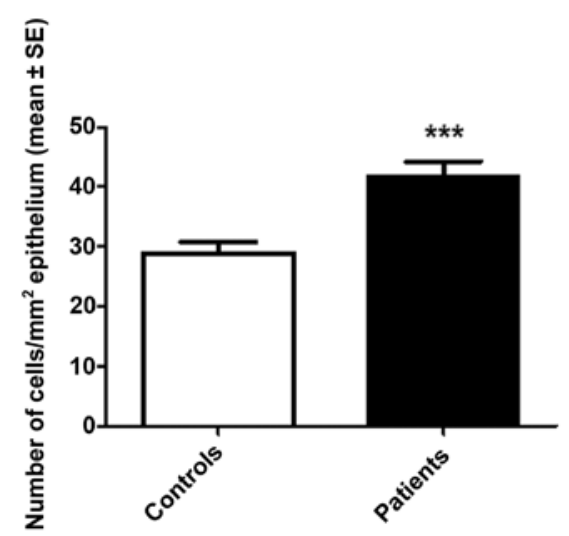

Figure 4. Serotonin-positive cell density in the colon of healthy controls and patients with lymphocytic colitis. ${ }^{* * *} \mathrm{P}>0.001$.

of the same autoimmune pathogenesis observed in the small intestine. The coexistence of celiac disease and LC makes it necessary to further examine patients with celiac disease who do not respond to a gluten-free diet. Thus, one of the first tasks in clinical practice is to exclude the possibility of celiac disease in patients exhibiting LC symptomology.

\section{Pathogenesis}

It is generally accepted that LC is secondary to an abnormal immune reaction in predisposed individuals. Gastrointestinal 
infections, drugs and/or autoimmunity possibely trigger this reaction. An abnormality in the colon neuroendocrine system has also been reported and seems to play a role in the pathophysiology of LC.

Gastrointestinalinfections. Gastrointestinal infection as an etiological factor of LC is supported by a case report of a 19 -year-old patient who developed LC following Campylobacter infection (52), and by a significant seasonal pattern in the incidence of LC (53). Associations with Clostridium difficile, Yersinia enterocolitica and Campylobacter jejuni have been observed in collagenous colitis, which is a disease related to LC (54-56). The initial inflammatory response following gastrointestinal infection shows an increase in $\mathrm{CD}^{+}$lymphocytes, $\mathrm{CD} 8$ intraepithelial lymphocytes and calprotectin-positive macrophages (57). These changes rapidly diminish in most subjects; however, a small number of patients with persistent symptoms fail to show this decline (57). This process can commence irrespective of the type of infectious agents (i.e. virus, bacteria or protozoa). Consequently, a report of no association being found between anti-Yersinia antibodies and LC in 19 patients does not exclude an infectious genesis for LC (58). The issue still remains however, of why only a proportion of patients that suffer gastroenteritis develop LC. Genetic factors may be of importance, since variants of the matrix metalloproteinase- 9 (MMP-9) gene have been observed in collagenous colitis (59).

A role for gastrointestinal infections in the pathogenesis of LC has been supported by the striking similarity between LC and post-infectious IBS (PI-IBS). These conditions have a similar clinical presentation and both can regress spontaneously $(57,60)$. Both LC and PI-IBS show an intra-epithelial and submucosal infiltration of lymphocytes and mast cells, and exhibit a high density of colonic serotonin and peptide YY (PYY) cells $(40,61-64)$. These similarities have prompted suggestions that LC and PI-IBS are the same disorder (62).

Drugs. A strong association exists between certain drugs and LC (65-67). There are reported cases of both the symptoms and the colonic histopathological changes disappearing following termination of the drug treatment and returning after the re-introduction of the drug treatment (65-67). The implicated drugs include non-steroidal anti-inflammatory drugs (NSAIDs), $\beta$-blockers, histamine-2 receptor blockers, proton pump inhibitors, statins, as well as others. NSAIDs are known to induce colonic and small intestinal inflammation and to cause relapse of inflammatory bowel disease (67-69). Patients with LC often have arthralgia, and the association with NSAIDs can thus be confounded (17). It is noteworthy that the age at which the incidence of LC peaks (i.e., 60 years) corresponds to when treatment with $\beta$-blockers, statins and low-dose aspirin are common for cardiovascular diseases.

Autoimmunity. Several studies have demonstrated an association between LC and autoimmune diseases, such as celiac disease, diabetes mellitus, arthritis and thyroid diseases $(21,70)$. Moreover, patients with LC exhibit positivity in the antinuclear antibody (ANA) test (21). Associations between microscopic colitis and the TNF2 allele, HLA A1 allele and cytokine gene polymorphism in the IL-6-174 GG genotype have been reported (71-73).
Abnormalities in colonic neuroendocrine system. Colonic nitric oxide (NO) levels are markedly increased in patients with LC, which is due to an increase in NO synthase levels in the colonic epithelium (74-76). The colonic serotonin (Figs. 4 and 5) and PYY cell densities (Figs. 6 and 7) have been reported to be extremely high in patients with LC (62). NO increases intestinal motility and stimulates the intestinal secretion of water and electrolytes $(77,78)$. Serotonin activates the submucosal sensory branch of the enteric nervous system, and controls gastrointestinal motility and chloride secretion via inter-neurons and motor neurons $(79,80)$. PYY stimulates the absorption of water and electrolytes, and is a major regulator of the 'ileal brake' (81). Furthermore, PYY inhibits prostaglandin E2 and vasoactive intestinal polypeptide (VIP) actiation, which stimulate intestinal fluid secretion (82-84). The administration of PYY has been shown to inhibit diarrhea in experimental mouse models by reducing intestinal fluid secretion and delaying colonic transit (85).

Hypothesis. Serotonin secretion by enterochromaffin (EC) cells can be enhanced or attenuated by the secretory products of immune cells, such as $\mathrm{CD} 4^{+} \mathrm{T}$ cells (86). Furthermore, serotonin modulates the immune response (86). EC cells are in contact with or very close to $\mathrm{CD}^{+}$and $\mathrm{CD} 20^{+}$lymphocytes and several serotonergic receptors have been characterized in lymphocytes, monocytes, macrophages and dendritic cells (87-91). It is therefore conceivable that the increase in colonic serotonin cell density in patients with $\mathrm{LC}$ results from the interaction between lymphocytes and EC cells. Serotonin stimulates NO secretion, which is partly responsible for its effects on intestinal motility and thus secretion is partly due to the activation of NO $(78,88-91)$. It is reasonable to assume that the increase in colonic NO levels is caused by the increase in serotonin levels observed in patients with LC. The increase in colonic serotonin and $\mathrm{NO}$ levels in patients with $\mathrm{LC}$ accelerates intestinal motility and water and electrolyte secretion observed in LC diarrhea, which is of secretory character (92). Accelerated intestinal motility and secretion may be the cause of the compensatory secondary increase in PYY levels in the colon of patients with LC. This compensatory mechanism may explain the occurrence of intermittent diarrhea in some patients with LC, as an increase in PYY levels can compensate for the increased secretion and motility for only short periods ot time (Fig. 8).

\section{Treatment}

The drugs commonly used in the treatment of LC are loperamide, 5-aminosalicylates, budesonide, prednisolone, bismuth subsalicylate, immunosuppression and anti-TNF- $\alpha$ therapies (17,93-95) (Fig. 9). Cholestyramine has also been recommended for the treatment of $\mathrm{LC}$, but its clinical response was possibly due to the fact that the patients treated suffered from bile acid malabsorption (93). Loperamide, which is a symptomatic non-specific anti-diarrheal agent, is often the first-line therapy prescribed. It is administered as a tablet of $2 \mathrm{mg}$ (up to 8 tablets taken daily if necessary). A complete or partial response to loperamide has been observed in 70-73\% of patients $(11,22)$. 5-Aminosalicylates, such as sulfasalazine and mesalamine are a common therapy for LC in clinical practice due to positive responses and tolerance in the majority 

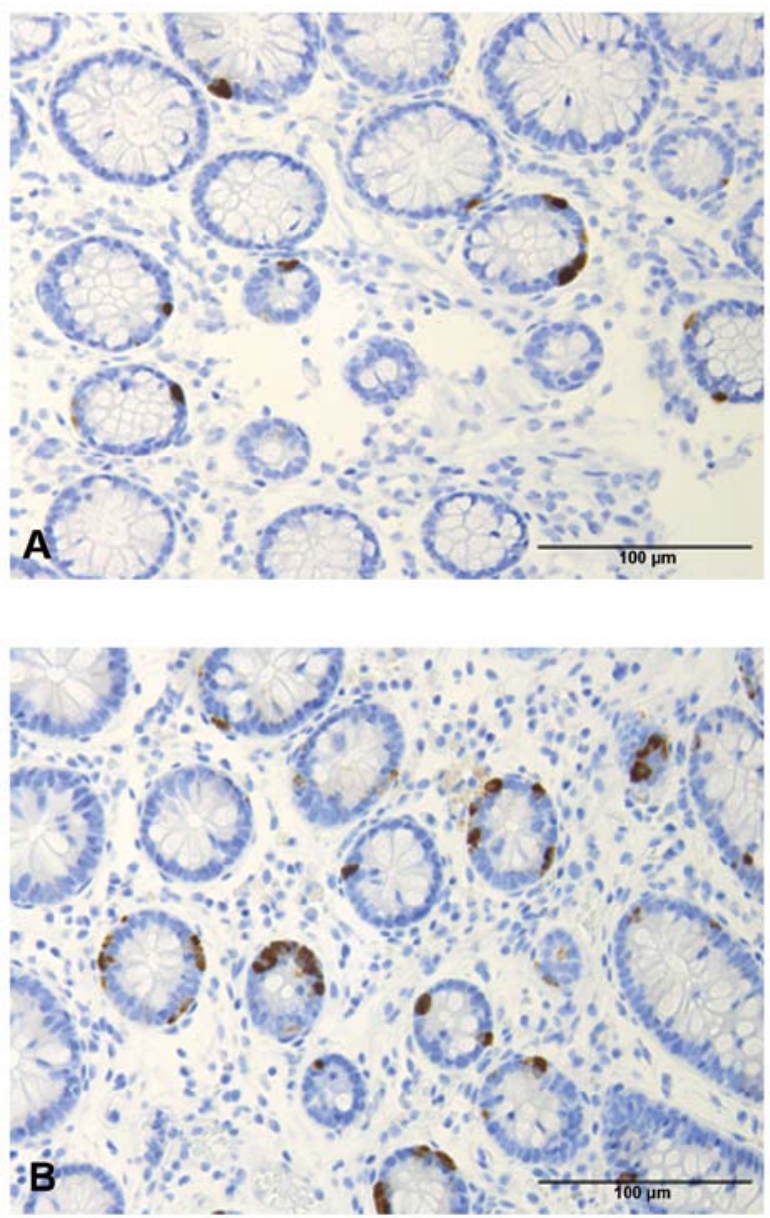

Figure 5. Colonic serotonin-positive cells in (A) healthy controls and (B) patients with lymphocytic colitis.

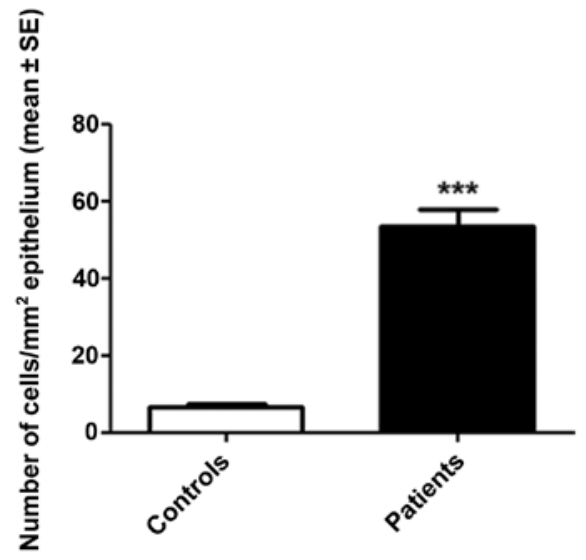

Figure 6. Density of peptide YY cells in the colon of healthy controls and patients with lymphocytic colitis. ${ }^{* * *} \mathrm{P}>0.001$.

of patients $(22,96)$. However, there have been several reports of 5 -aminosalicylates inducing remission in $<50 \%$ of patients $(25,97)$. Budesonide is the most documented drug used in the treatment of LC. It is a glucocorticoid with no significant adverse events that are known to occur in systemic treatments with corticosteroids. This is due to its limited systemic availability caused by the extensive first-pass hepatic metabolism by cytochrome P-450 enzymes. Clinical remission has been
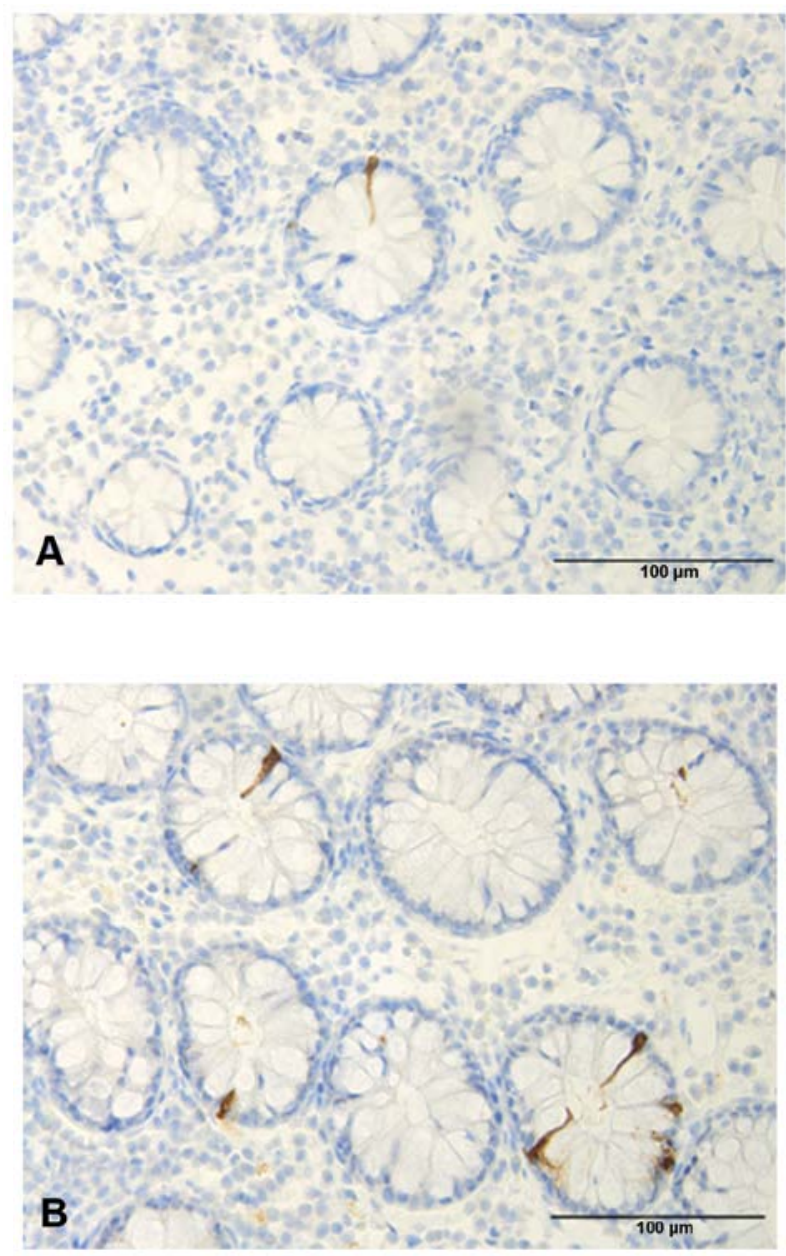

Figure 7. Colonic peptide YY cells in (A) healthy controls and (B) patients with lymphocytic colitis.
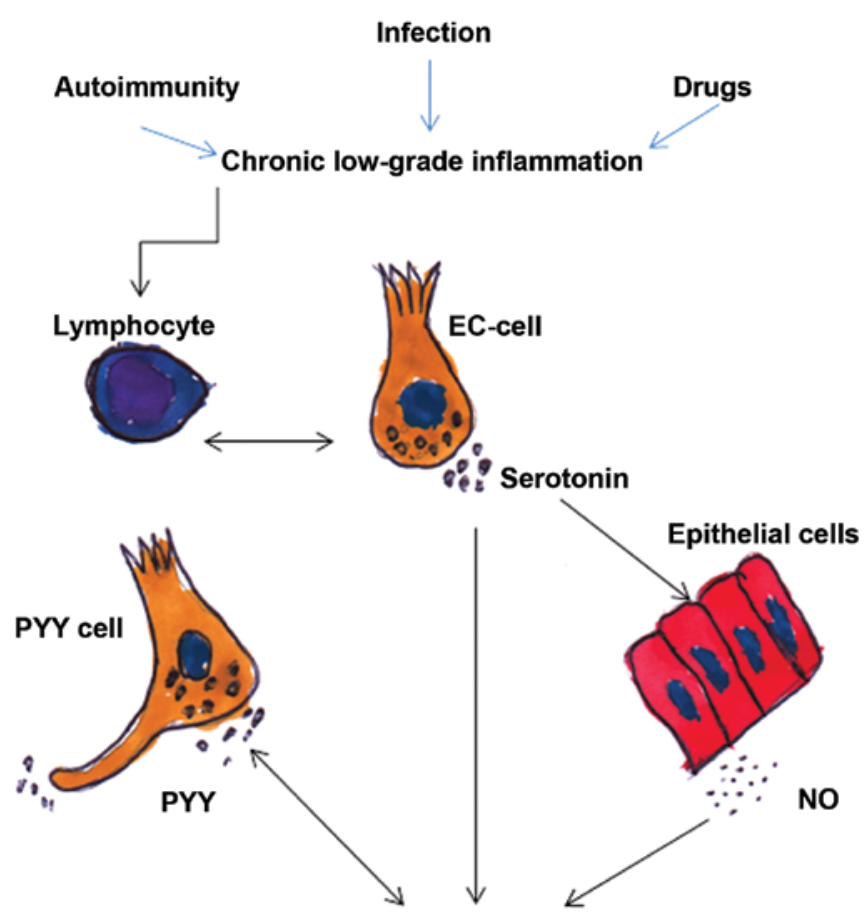

Accelerated intestinal motility and secretion (diarrhea)

Figure 8. Schematic diagram of the possible pathogenesis of lymphocytic colitis. 


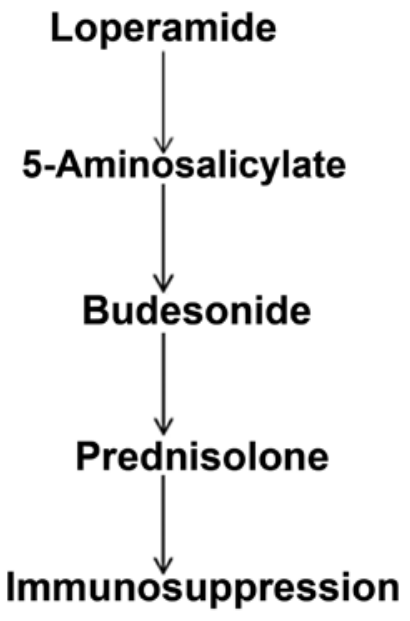

Figure 9. Suggested drug-treatment algorithm for lymphocytic colitis.

reported in $82-86 \%$ of patients with LC following 6-weeks of treatment with $9 \mathrm{mg}$ of budesonide daily $(11,98)$. Relapse after cessation of budesonide treatment has been shown to occur in $14-44 \%$ of patients after $1-7$ months $(11,98)$. The relapsed patients responded to new treatment and remained in clinical remission with a maintenance therapy of a median daily budesonide dose of $3 \mathrm{mg}(11,98)$. Four weeks of treatment with prednisolone at $40 \mathrm{mg}$ daily tapered by $5 \mathrm{mg} /$ week resulted in complete or partial clinical remission in $87-94 \%$ of patients with LC $(11,99)$. However, the majority of these patients relapsed after termination of the therapy $(11,22)$. Bismuth subsalicylate at a dose of 2 or 3 tablets ( $262 \mathrm{mg}$ each) 3 or 4 times daily for 8 weeks induced remission in the majority of patients which was sustained up to 7-23 months $(22,100)$. No toxicity was absorbed despite the high dose of bismuth, which may have been due to the short treatment duration or low bismuth absorption. However, treatment with bismuth is not without any toxic effects and its availability is limited in certain countries. Treatment with azathioprine at $2-2.5 \mathrm{mg} / \mathrm{kg} /$ day, with 6-mercaptopurine at $1 \mathrm{mg} / \mathrm{kg} /$ day both indefinitely, and anti-TNF- $\alpha$ have produced good results in patients with refractory LC $(94,99,101)$. The indications for surgical therapy are limited (102).

Concomitant drug use should be assessed and drugs that potentially cause drug-induced LC should be discontinued, if possible. Considering the possibility that LC and PI-IBS can be the same disorder, diet, regular exercise and probiotic intake recommendations provided to patients with IBS (103-105) should also be recommended for patients with LC. The benign course and high rate of spontaneous remission of LC denotes that drugs with severe side-effects should be avoided if possible. Furthermore, the drug cost and drug coverage may be limiting factors for some patients. These aspects should be taken into account when selecting treatment. An algorithmic approach to the treatment of LC is recommended (Fig. 9).

\section{Conclusion}

LC is not a rare disorder as previously thought. Although LC is considered a diarrheal disorder, it can present with other symptoms, such as constipation or abdominal pain. Colonic biopsy samples in patients presenting with symptoms other than diarrhea and with a macroscopically normal colon should be taken more frequently than routinely done at present. The density of colonic chromogranin A-positive cells may be used as a diagnostic tool for LC. The cause of LC may be a low-grade inflammation with an interaction with the colonic neuroendocrine system. There are good reasons to suspect that LC and PI-IBS are one and the same disorder. The benign course and high rate of spontaneous remission, as well as the drug cost and drug coverage should be taken into accout when making decisions regarding treatment. An algorithmic approach to the treatment of LC is preferable.

\section{References}

1. Read NW, Krejs GJ, Read MG, Santa Ana CA, Morawski SG and Fordtran JS: Chronic diarrhea of unknown origin. Gastroenterology 78: 264-271, 1980.

2. Chande N, MacDonald JK and McDonald JW: Interventions for treating microscopic colitis: a Cochrane Inflammatory Bowel Disease and Functional Bowel Disorders Review Group systematic review of randomized trials. Am J Gastroenterol 104: 235-241; quiz 234, 242, 2009.

3. Pardi DS: Microscopic colitis: an update. Inflamm Bowel Dis 10: 860-870, 2004

4. Pardi DS and Kelly CP: Microscopic colitis. Gastroenterology 140: 1155-1165, 2011.

5. Yen EF and Pardi DS: Review of the microscopic colitides. Curr Gastroenterol Rep 13: 458-464, 2011.

6. Olesen M, Eriksson S, Bohr J, Jarnerot G and Tysk C: Microscopic colitis: a common diarrhoeal disease. An epidemiological study in Orebro, Sweden, 1993-1998. Gut 53: 346-350, 2004.

7. Guagnozzi D, Lucendo AJ, Angueira-Lapena T, GonzalezCastillo S and Tenias Burillo JM: Prevalence and incidence of microscopic colitis in patients with diarrhoea of unknown aetiology in a region in central Spain. Dig Liver Dis 44: 384-388, 2012.

8. Fernandez-Banares F, Salas A, Forne M, Esteve M, Espinos J and Viver JM: Incidence of collagenous and lymphocytic colitis: a 5-year population-based study. Am J Gastroenterol 94: 418-423, 1999.

9. Fernandez-Banares F, Salas A, Esteve M, et al: Evolution of the incidence of collagenous colitis and lymphocytic colitis in Terrassa, Spain: a population-based study. Inflamm Bowel Dis 17: 1015-1020, 2011.

10. Bjornbak C, Engel PJ, Nielsen PL and Munck LK: Microscopic colitis: clinical findings, topography and persistence of histopathological subgroups. Aliment Pharmacol Ther 34: 1225-1234, 2011.

11. Agnarsdottir M, Gunnlaugsson $\mathrm{O}$, Orvar KB, et al: Collagenous and lymphocytic colitis in Iceland. Dig Dis Sci 47: 1122-1128, 2002.

12. Pardi DS, Loftus EV Jr, Smyrk TC, et al: The epidemiology of microscopic colitis: a population based study in Olmsted County, Minnesota. Gut 56: 504-508, 2007.

13. Williams JJ, Kaplan GG, Makhija S, et al: Microscopic colitisdefining incidence rates and risk factors: a population-based study. Clin Gastroenterol Hepatol 6: 35-40, 2008.

14. Rasmussen MA and Munck LK: Systematic review: are lymphocytic colitis and collagenous colitis two subtypes of the same disease - microscopic colitis? Aliment Pharmacol Ther 36: 79-90, 2012.

15. Fernandez-Banares F, Esteve M and Viver JM: Epidemiology of microscopic colitis. Gut 56: 1033, 2007.

16. Brown WR and Tayal S: Microscopic colitis. A review. J Dig Dis 14: 277-281, 2013.

17. Yen EF and Pardi DS: Review article: microscopic colitis - lymphocytic, collagenous and 'mast cell' colitis. Aliment Pharmacol Ther 34: 21-32, 2011.

18. Mohamed N, Marais M and Bezuidenhout J: Microscopic colitis as a missed cause of chronic diarrhea. World J Gastroenterol 17: 1996-2002, 2011.

19. Pascua MF, Kedia P, Weiner MG, Holmes J, Ellenberg J and Lewis JD: Microscopic colitis and medication use. Clin Med Insights Gastroenterol 2010: 11-19, 2010. 
20. Munch A, Aust D, Bohr J, et al: Microscopic colitis: Current status, present and future challenges: statements of the European Microscopic Colitis Group. J Crohns Colitis 6: 932-945, 2012.

21. Mahajan D, Goldblum JR, Xiao SY, Shen B and Liu X: Lymphocytic colitis and collagenous colitis: a review of clinicopathologic features and immunologic abnormalities. Adv Anat Pathol 19: 28-38, 2012.

22. Pardi DS, Ramnath VR, Loftus EV Jr, Tremaine WJ and Sandborn WJ: Lymphocytic colitis: clinical features, treatment, and outcomes. Am J Gastroenterol 97: 2829-2833, 2002.

23. Mullhaupt B, Guller U, Anabitarte M, Guller R and Fried M: Lymphocytic colitis: clinical presentation and long term course. Gut 43: 629-633, 1998.

24. Barta Z, Mekkel G, Csipo I, et al: Microscopic colitis: a retrospective study of clinical presentation in 53 patients. World J Gastroenterol 11: 1351-1355, 2005.

25. Olesen M,Eriksson S, Bohr J,Jarnerot G and Tysk C: Lymphocytic colitis: a retrospective clinical study of 199 Swedish patients. Gut 53: 536-541, 2004.

26. Koskela RM, Niemela SE, Karttunen TJ and Lehtola JK: Clinical characteristics of collagenous and lymphocytic colitis. Scand J Gastroenterol 39: 837-845, 2004.

27. Baert F, Wouters K, D'Haens G, et al: Lymphocytic colitis: a distinct clinical entity? A clinicopathological confrontation of lymphocytic and collagenous colitis. Gut 45: 375-381, 1999.

28. Sveinsson OA, Orvar KB, Birgisson S, Agnarsdottir M and Jonasson JG: Clinical features of microscopic colitis in a nationwide follow-up study in Iceland. Scand J Gastroenterol 43: 955-960, 2008

29. Kao KT, Pedraza BA, McClune AC, et al: Microscopic colitis: a large retrospective analysis from a health maintenance organization experience. World J Gastroenterol 15: 3122-3127, 2009.

30. Liszka L, Woszczyk D and Pajak J: Histopathological diagnosis of microscopic colitis. J Gastroenterol Hepatol 21: 792-797, 2006

31. Veress B, Lofberg R and Bergman L: Microscopic colitis syndrome. Gut 36: 880-886, 1995.

32. Thijs WJ, van Baarlen J, Kleibeuker JH and Kolkman JJ: Microscopic colitis: prevalence and distribution throughout the colon in patients with chronic diarrhoea. Neth J Med 63: 137-140, 2005.

33. Fine KD, Seidel RH and Do K: The prevalence, anatomic distribution, and diagnosis of colonic causes of chronic diarrhea. Gastrointest Endosc 51: 318-326, 2000.

34. Matteoni CA, Wang N, Goldblum JR, Brzezinski A, Achkar E and Soffer EE: Flexible sigmoidoscopy for the detection of microscopic colitis. Am J Med 108: 416-418, 2000.

35. Taupenot L, Harper KL and O'Connor DT: The chromograninsecretogranin family. N Engl J Med 348: 1134-1149, 2003.

36. Wiedenmann B and Huttner WB: Synaptophysin and chromogranins/secretogranins - widespread constituents of distinct types of neuroendocrine vesicles and new tools in tumor diagnosis. Virchows Arch B Cell Pathol Incl Mol Pathol 58: 95-121, 1989.

37. Deftos LJ: Chromogranin A: its role in endocrine function and as an endocrine and neuroendocrine tumor marker. Endocr Rev 12: 181-187, 1991.

38. El-Salhy M, Lomholt-Beck B and Gundersen D: High chromogranin A cell density in the colon of patients with lymphocytic colitis. Mol Med Rep 4: 603-605, 2011.

39. El-Salhy M, Gundersen D, Hatlebakk JG and Hausken T: Chromogranin A cell density as a diagnostic marker for lymphocytic colitis. Dig Dis Sci 57: 3154-3159, 2012.

40. El-Salhy M, Gundersen D, Hatlebakk JG and Hausken T: Irritable Bowel Syndrome: Diagnosis Pathogenesis and Treatment Options. Nova Science Publisher, New York, 2012.

41. El-Salhy M, Halwe J, Lomholt-Beck B and Gundersen D: The prevalence of inflammatory bowel diseases and microscopic colitis and colorectal cancer in patients with irritable bowel syndrome. Gastroenterology Insights 3: 7-10, 2011.

42. Madisch A, Bethke B, Stolte M and Miehlke S: Is there an association of microscopic colitis and irritable bowel syndrome - a subgroup analysis of placebo-controlled trials. World J Gastroenterol 11: 6409,2005

43. Rahman MA, Raihan AS, Ahamed DS, et al: Symptomatic overlap in patients with diarrhea predominant irritable bowel syndrome and microscopic colitis in a sub group of Bangladeshi population. Bangladesh Med Res Counc Bull 38: 33-38, 2012.

44. Arevalo F, Aragon V, Montes P, Guzman E and Monge E: Increase of intraepithelial lymphocytes in patients with irritable bowel syndrome. Rev Gastroenterol Peru 31: 315-318, 2011 (In Spanish).
45. El-Salhy M, Lomholt-Beck B and Hausken T: Chromogranin A as a possible tool in the diagnosis of irritable bowel syndrome. Scand J Gastroenterol 45: 1435-1439, 2010.

46. Dewar DH, Donnelly SC, McLaughlin SD, Johnson MW, Ellis HJ and Ciclitira PJ: Celiac disease: management of persistent symptoms in patients on a gluten-free diet. World J Gastroenterol 18: 1348-1356, 2012.

47. Wolber R, Owen D and Freeman H: Colonic lymphocytosis in patients with celiac sprue. Hum Pathol 21: 1092-1096, 1990.

48. Green PH, Yang J, Cheng J, Lee AR, Harper JW and Bhagat G: An association between microscopic colitis and celiac disease. Clin Gastroenterol Hepatol 7: 1210-1216, 2009.

49. Fraser AG, Warren BF, Chandrapala R and Jewell DP: Microscopic colitis: a clinical and pathological review. Scand J Gastroenterol 37: 1241-1245, 2002.

50. Abdulkarim AS and Murray JA: Celiac disease. Curr Treat Options Gastroenterol 5: 27-38, 2002.

51. Ciclitira PJ, King AL and Fraser JS: AGA technical review on Celiac Sprue. American Gastroenterological Association. Gastroenterology 120: 1526-1540, 2001.

52. Perk G, Ackerman Z, Cohen P and Eliakim R: Lymphocytic colitis: a clue to an infectious trigger. Scand J Gastroenterol 34: 110-112, 1999.

53. LaSala PR, Chodosh AB, Vecchio JA, Schned LM and Blaszyk H: Seasonal pattern of onset in lymphocytic colitis. J Clin Gastroenterol 39: 891-893, 2005.

54. Erim T, Alazmi WM, O'Loughlin CJ and Barkin JS: Collagenous colitis associated with Clostridium difficile: a cause effect? Dig Dis Sci 48: 1374-1375, 2003.

55. Bohr J, Nordfelth R, Jarnerot G and Tysk C: Yersinia species in collagenous colitis: a serologic study. Scand J Gastroenterol 37: 711-714, 2002.

56. Makinen M, Niemela S, Lehtola J and Karttunen TJ: Collagenous colitis and Yersinia enterocolitica infection. Dig Dis Sci 43: 1341-1346, 1998

57. Spiller RC, Jenkins D, Thornley JP, et al: Increased rectal mucosal enteroendocrine cells, T lymphocytes, and increased gut permeability following acute Campylobacter enteritis and in post-dysenteric irritable bowel syndrome. Gut 47: 804-811, 2000.

58. Tamboli CP, Good MR, Reynolds EM, Sharma P and Mitros FA: Anti-Yersinia antibodies are not associated with microscopic colitis in an American case-control study. Scand J Gastroenterol 46: 1442-1448, 2011.

59. Madisch A, Hellmig S, Schreiber S, Bethke B, Stolte M and Miehlke S: Allelic variation of the matrix metalloproteinase- 9 gene is associated with collagenous colitis. Inflamm Bowel Dis 17: 2295-2298, 2011

60. Spiller R and Garsed K: Postinfectious irritable bowel syndrome. Gastroenterology 136: 1979-1988, 2009.

61. Dunlop SP, Jenkins D, Neal KR and Spiller RC: Relative importance of enterochromaffin cell hyperplasia, anxiety, and depression in postinfectious IBS. Gastroenterology 125: $1651-1659,2003$.

62. El-Salhy M, Gundersen D, Hatlebakk JG and Hausken T: High densities of serotonin and peptide YY cells in the colon of patients with lymphocytic colitis. World J Gastroenterol 18: 6070-6075, 2012.

63. Park JH, Rhee PL, Kim G, et al: Enteroendocrine cell counts correlate with visceral hypersensitivity in patients with diarrhoeapredominant irritable bowel syndrome. Neurogastroenterol Motil 18: 539-546, 2006.

64. Kim HS, Lim JH, Park H and Lee SI: Increased immunoendocrine cells in intestinal mucosa of postinfectious irritable bowel syndrome patients 3 years after acute Shigella infection - an observation in a small case control study. Yonsei Med J 51: 45-51, 2010.

65. Beaugerie L and Pardi DS: Review article: drug-induced microscopic colitis - proposal for a scoring system and review of the literature. Aliment Pharmacol Ther 22: 277-284, 2005.

66. Fernandez-Banares F, Esteve M,Espinos JC, et al: Drug consumption and the risk of microscopic colitis. Am J Gastroenterol 102 324-330, 2007.

67. Bjarnason I, Hayllar J, MacPherson AJ and Russell AS: Side effects of nonsteroidal anti-inflammatory drugs on the small and large intestine in humans. Gastroenterology 104: 1832-1847, 1993.

68. Leung WK, Bjarnason I, Wong VW, Sung JJ and Chan FK: Small bowel enteropathy associated with chronic low-dose aspirin therapy. Lancet 369: 614, 2007. 
69. Takeuchi K, Smale S, Premchand P, et al: Prevalence and mechanism of nonsteroidal anti-inflammatory drug-induced clinical relapse in patients with inflammatory bowel disease. Clin Gastroenterol Hepatol 4: 196-202, 2006.

70. Tysk C, Bohr J, Nyhlin N, Wickbom A and Eriksson S: Diagnosis and management of microscopic colitis. World J Gastroenterol 14: 7280-7288, 2008.

71. Giardiello FM, Lazenby AJ, Yardley JH, et al: Increased HLA A1 and diminished HLA A3 in lymphocytic colitis compared to controls and patients with collagenous colitis. Dig Dis Sci 37: 496-499, 1992

72. Koskela RM, Karttunen TJ, Niemela SE, Lehtola JK, Ilonen J and Karttunen RA: Human leucocyte antigen and TNFalpha polymorphism association in microscopic colitis. Eur J Gastroenterol Hepatol 20: 276-282, 2008.

73. Koskela RM, Karttunen TJ, Niemela SE, Lehtola JK, Bloigu RS and Karttunen RA: Cytokine gene polymorphism in microscopic colitis association with the IL-6-174 GG genotype. Eur J Gastroenterol Hepatol 23: 607-613, 2011.

74. Lundberg JO, Herulf M, Olesen M, et al: Increased nitric oxide production in collagenous and lymphocytic colitis. Eur J Clin Invest 27: 869-871, 1997.

75. Olesen M, Middelveld R, Bohr J, et al: Luminal nitric oxide and epithelial expression of inducible and endothelial nitric oxide synthase in collagenous and lymphocytic colitis. Scand J Gastroenterol 38: 66-72, 2003.

76. Kolios G, Rooney N, Murphy CT, Robertson DA and Westwick J: Expression of inducible nitric oxide synthase activity in human colon epithelial cells: modulation by $\mathrm{T}$ lymphocyte derived cytokines. Gut 43: 56-63, 1998.

77. Mourad FH, Turvill JL and Farthing MJ: Role of nitric oxide in intestinal water and electrolyte transport. Gut 44: 143-147, 1999.

78. Kuwahara A, Kuramoto $\mathrm{H}$ and Kadowaki M: 5-HT activates nitric oxide-generating neurons to stimulate chloride secretion in guinea pig distal colon. Am J Physiol 275: G829-G834, 1998.

79. Gershon MD: Plasticity in serotonin control mechanisms in the gut. Curr Opin Pharmacol 3: 600-607, 2003

80. Kellum JM, Albuquerque FC, Stoner MC and Harris RP: Stroking human jejunal mucosa induces $5-\mathrm{HT}$ release and $\mathrm{Cl}-$ secretion via afferent neurons and 5-HT4 receptors. Am J Physiol 277: G515-G520, 1999.

81. Walsh JH: Gastrointestinal hormones. In: Physiology of the Gastrointestinal Tract. Johnson LR, Alpers DH, Christensen J, Jacobson ED and Walsh JH (eds). Raven Press, New York, pp1-128, 1994

82. Goumain M, Voisin T, Lorinet AM, et al: The peptide YYpreferring receptor mediating inhibition of small intestinal secretion is a peripheral Y(2) receptor: pharmacological evidence and molecular cloning. Mol Pharmacol 60: 124-134, 2001.

83. Souli A, Chariot J, Voisin T, et al: Several receptors mediate the antisecretory effect of peptide YY, neuropeptide Y, and pancreatic polypeptide on VIP-induced fluid secretion in the rat jejunum in vivo. Peptides 18: 551-557, 1997.

84. Whang EE, Hines OJ, Reeve JR Jr, et al: Antisecretory mechanisms of peptide YY in rat distal colon. Dig Dis Sci 42: 1121-1127, 1997.

85. Moriya R, Shirakura T, Hirose H, Kanno T, Suzuki J and Kanatani A: NPY Y2 receptor agonist PYY(3-36) inhibits diarrhea by reducing intestinal fluid secretion and slowing colonic transit in mice. Peptides 31: 671-675, 2010.

86. Khan WI and Ghia JE: Gut hormones: emerging role in immune activation and inflammation. Clin Exp Immunol 161: 19-27, 2010 .
87. Yang GB and Lackner AA: Proximity between 5-HT secreting enteroendocrine cells and lymphocytes in the gut mucosa of rhesus macaques (Macaca mulatta) is suggestive of a role for enterochromaffin cell 5-HT in mucosal immunity. J Neuroimmunol 146: 46-49, 2004.

88. Briejer MR, Akkermans LM, Meulemans AL, Lefebvre RA and Schuurkes JA: Nitric oxide is involved in 5-HT-induced relaxations of the guinea-pig colon ascendens in vitro. $\mathrm{Br} \mathrm{J}$ Pharmacol 107: 756-761, 1992

89. Stoner MC, Scherr AM, Lee JA, Wolfe LG and Kellum JM Nitric oxide is a neurotransmitter in the chloride secretory response to serotonin in rat colon. Surgery 128: 240-245, 2000.

90. Stoner MC and Kellum JM: Both serotonin and a nitric-oxide donor cause chloride secretion in rat colonocytes by stimulating cGMP. Surgery 130: 236-241, 2001.

91. Kadowaki M, Gershon MD and Kuwahara A: Is nitric oxide involved in 5-HT-induced fluid secretion in the gut? Behav Brain Res 73: 293-296, 1996.

92.Protic M, Jojic N, Bojic D, et al: Mechanism of diarrhea in microscopic colitis. World J Gastroenterol 11: 5535-5539, 2005.

93. Stroehlein JR: Microscopic colitis. Curr Treat Options Gastroenterol 10: 231-236, 2007.

94. Esteve M, Mahadevan U, Sainz E, Rodriguez E, Salas A and Fernandez-Banares F: Efficacy of anti-TNF therapies in refractory severe microscopic colitis. J Crohns Colitis 5: 612-618, 2011

95. Chande N: Microscopic colitis: an approach to treatment. Can J Gastroenterol 22: 686-688, 2008.

96. Fernandez-Banares F, Salas A, Esteve M, Espinos J, Forne M and Viver JM: Collagenous and lymphocytic colitis: evaluation of clinical and histological features, response to treatment, and long-term follow-up. Am J Gastroenterol 98: 340-347, 2003.

97. Calabrese C, Fabbri A, Areni A, Zahlane D, Scialpi C and Di Febo G: Mesalazine with or without cholestyramine in the treatment of microscopic colitis: randomized controlled trial. J Gastroenterol Hepatol 22: 809-814, 2007.

98. Miehlke S, Madisch A, Karimi D, et al: Budesonide is effective in treating lymphocytic colitis: a randomized double-blind placebo-controlled study. Gastroenterology 136: 2092-2100, 2009.

99. Pardi DS, Loftus EV Jr, Tremaine WJ and Sandborn WJ Treatment of refractory microscopic colitis with azathioprine and 6-mercaptopurine. Gastroenterology 120: 1483-1484, 2001.

100. Fine KD and Lee EL: Efficacy of open-label bismuth subsalicylate for the treatment of microscopic colitis. Gastroenterology 114: 29-36, 1998.

101. Vennamaneni SR and Bonner GF: Use of azathioprine or 6-mercaptopurine for treatment of steroid-dependent lymphocytic and collagenous colitis. Am J Gastroenterol 96: 2798-2799, 2001.

102. Varghese L, Galandiuk S, Tremaine WJ and Burgart LJ: Lymphocytic colitis treated with proctocolectomy and ileal J-pouch-anal anastomosis: report of a case. Dis Colon Rectum 45: 123-126, 2002.

103. Ostgaard H, Hausken T, Gundersen D and El-Salhy M: Diet and effects of diet management on quality of life and symptoms in patients with irritable bowel syndrome. Mol Med Rep 5: 1382-1390, 2012.

104. El-Salhy M, Ostgaard H, Gundersen D, Hatlebakk JG and Hausken T: The role of diet in the pathogenesis and management of irritable bowel syndrome (Review). Int J Mol Med 29: 723-731, 2012.

105. El-Salhy M, Lillebø E, Reinemo A, Salmelid L and Hausken T: Effects of a health program comprising reassurance, diet management, probiotics administration and regular exercise on symptoms and quality of life in patients with irritable bowel syndrome. Gastroenterology Insights 2: 21-26, 2010. 